\title{
Predictors of Caregiver Communication About Reproductive and Sexual Health and Sensitive Sex Topics
}

\author{
Tiarney D. Ritchwood', Courtney Peasant ${ }^{2}$, \\ Terrinieka W. Powell ${ }^{3}$, Tamara Taggart ${ }^{4}$, \\ Giselle Corbie-Smith ${ }^{5}$, and Aletha Y. Akers ${ }^{6}$
}

\begin{abstract}
Numerous studies examining parent-teen communication about sex (PTCS) have focused on reproductive and sexual health information (i.e., pregnancy, physical development, contraception), with significantly fewer addressing communication about sensitive sex topics (i.e., sexual pleasure, masturbation). This study compares predictors of communication about reproductive and sexual health to those of sensitive sex topics with early adolescents. Participants were 465 rural caregivers and their African American youth. Positive attitudes and self-efficacy for PTCS, open communication style, and older youth age predicted caregiver reports of communication about reproductive and sexual health topics. Open communication style and selfefficacy for PTCS predicted caregiver reports of communication about sensitive sex topics. For youth, only older age and being female predicted communication about reproductive and sexual health, while only being

\footnotetext{
'Department of Public Health Sciences, Medical University of South Carolina, Charleston, SC, USA ${ }^{2}$ Center for Interdisciplinary Research on AIDS, Yale University. New Haven, CT, USA ${ }^{3}$ Johns Hopkins Bloomberg School of Public Health, Baltimore, MD, USA ${ }^{4}$ Department of Health Behavior, University of North Carolina at Chapel Hill, Chapel Hill, NC, USA.

${ }^{5}$ Department of Social Medicine, Center for Health Equity Research, University of North Carolina at Chapel Hill, 333 S. Columbia St., Chapel Hill, NC, USA.

${ }^{6}$ The Craig Dalsimer Division of Adolescent Medicine, The Children's Hospital of Philadelphia, Philadelphia, PA, USA.
}

\section{Corresponding Author:}

Tiarney D. Ritchwood, Department of Public Health Sciences, Medical University of South Carolina, 135 Cannon Street, Suite 303, Charleston, SC 29425, USA.

Email: ritchwoo@musc.edu 
female predicted communication about sensitive sex topics. This study may inform interventions that seek to increase PTCS by highlighting strategies for improving communication about both reproductive and sensitive sex topics.

\section{Keywords}

parent-teen communication, sexual behavior, sensitive sex, African Americans

Rural African American youth report an early age of sex initiation and are at high risk for unplanned pregnancy and sexually transmitted infections (STIs; Centers for Disease Control and Prevention, 2011, 2015; Epstein et al., 2014; Farmer et al., 2004). Parent-teen communication about sex (PTCS) is an important, well-documented strategy that has been associated with safer sexual practices among youth, including increased contraception and condom use (Akers, Holland, \& Bost, 2011; Sutton, Lasswell, Lanier, \& Miller, 2014; Widman, Choukas-Bradley, Noar, Nesi, \& Garrett, 2016). PTCS plays an important role in the sexual socialization of youth, with parents acting as change agents uniquely positioned to communicate their beliefs and values regarding sexual behavior to their adolescents prior to sex initiation (Jaccard, Dodge, \& Dittus, 2002; Miller et al., 2009). However, little is known about the diversity of topics covered in PTCS during early adolescence, the frequency of such discussions, or whether the predictors of PTCS differ by the type of topics discussed. Therefore, the current study aims to develop a greater understanding of the types of sexual topics covered during PTCS between rural African American youth and their caregivers.

Parent-led sexuality education allows parents to provide sexual health information to their youth in a manner that is consistent with their values and beliefs. Moreover, unlike school-based programs, parents are able to tailor this information with respect to their early adolescents' life experiences and social and community context (Jaccard et al., 2002). They are also able to exert an influence throughout their adolescents' development, enabling them to affect youths' behaviors and beliefs in various contexts. Caregivers, for example, have an extended reach and influence that enables them to direct their early adolescents toward age-appropriate activities and provide them with regular opportunities to discuss sexual health topics. Moreover, caregivers have the opportunity to tailor parental monitoring and supervision according to their youths' temperaments and characteristics (Jaccard et al., 2002). Previous research has shown that youth, in fact, prefer that their caregivers engage them conversations about sex (e.g., O’Donnell et al., 2007). 
PTCS may be protective against unsafe sexual practices among early African American youth if timed appropriately (Brody et al., 2005). Previous research, for example, has linked PTCS with early adolescents to delayed sex initiation and greater subsequent condom use (Bradley, Leichliter, \& Gift, 2013; Guilamo-Ramos et al., 2012). Moreover, PTCS has been linked to increased communication between adolescents and their partners about sex and condom use (Widman, Choukas-Bradley, Helms, Golin, \& Prinstein, 2014). These findings are consistent with the structural ecosystems perspective, which posits that repetitive and frequent patterns of interaction among people within a social system has an effect on the beliefs and behaviors of those within and external to the system (Szapocznik \& Coatsworth, 1999). Applied to PTCS, this perspective suggests that frequent and effective communication between parents and youth about sexual health topics could serve as a model for the way in which youth communicate with their future sexual partners about sex. Taken together, these findings highlight the importance of PTCS to adolescent sexual outcomes.

An integrated behavioral framework is particularly useful in identifying and understanding predictors of PTCS (Fishbein, 2000). According to this framework, motivation and behavioral intentions affect knowledge, beliefs, attitudes, and self-efficacy, which are key drivers of behavioral outcomes. As such, it is critical that we determine which factors serve as strong enough motivators to lead caregivers to develop intentions to engage their youth in PTCS. Intentions to act, however, are not enough to cause actual behavior. Instead, whether she actually engages her youth in PTCS depends on her knowledge, attitudes, beliefs, and self-efficacy regarding PTCS. Consistent with this framework, several factors have been linked to PTCS among older adolescents, including (a) perceived knowledge to answer questions and provide clear explanations, (b) beliefs that such conversations would not cause embarrassment to either the adolescent or themselves, (c) beliefs that the outcomes of such conversations would be positive, (d) reports of high self-efficacy to have such conversations, (e) beliefs that having such conversations made them responsible parents, (f) the absence of fear of encouraging sexual activity, and (g) demographic characteristics, such as parent age or gender (Guilamo-Ramos, Jaccard, Dittus, \& Collins, 2008; Jerman \& Constantine, 2010; Williams, Pichon, \& Campbell, 2015; Wyckoff et al., 2008). These findings are also consistent with social cognitive theory (SCT; Bandura, 1989), which posits that knowledge, skill, and self-efficacy for PTCS increases the chances that a parent will engage in PTCS. Moreover, SCT supports the notion that parents seek environmental cues (e.g., age, physical development, expressed curiosity, and actual sexual behavior) to indicate their youths' readiness for PTCS. Previous research, however, has shown that 
parents often underestimate their youths' interest in sex and readiness for sexual communication, with one study showing that youth between ages 9 and 12 years report readiness for sex or sexual communication (Miller et al., 2012). Additionally, parents are more likely to talk to their children about sex if they have a close relationship in which they generally communicate well with their child, often viewed as a proxy for relationship quality (Lammers, Ireland, Resnick, \& Blum, 2000; Regnerus \& Luchies, 2006). A closer parent-teen relationship and a more open communication style could help youth better understand their parents' attitudes and beliefs about early sexual activity. This is particularly important given the previous research linking maternal sexual attitudes to their youths' sexual attitudes and behaviors (e.g., Dittus, Miller, Kotchick, \& Forehand, 2004). However, less is known about the factors that predict PTCS among caregivers of rural African American, early adolescents. Such factors may differ from those that influence PTCS with older adolescents, as most early adolescents have not yet initiated sex and may not have embarked on a romantic relationship, which are both behaviors that caregivers may use as cues that their youth are ready for PTCS (Beckett et al., 2010). By neglecting to intervene on factors that affect PTCS among early adolescents, interventions may inadvertently miss an opportunity to increase safe sexual behaviors of these youth as they develop and initiate sexual behavior.

Studies investigating the significance of PTCS often inquire about a limited range of topics (Dyson \& Smith, 2012). In fact, the majority of studies on PTCS have focused on the provision of reproductive and sexual health information, which includes topics emphasizing sexual development (i.e., menstruation, physical development) and the risk prevention due to the consequences of adolescent sexual activity (i.e., pregnancy, condom use, STI, contraception, abortion; Aspy et al., 2007; Donaldson, Lindberg, Ellen, \& Marcell, 2013; Eisenberg, Sieving, Bearinger, Swain, \& Resnick, 2006; Miller et al., 2011; Robert \& Sonenstein, 2010). While discussions of reproductive and sexual health are important, discussions of sensitive sex topics, or those that emphasize the positive aspects of sexuality (e.g., sexual desire and pleasure, types of sex, masturbation, and nocturnal emission) might also be important for youths' subsequent sexual relationships, particularly as it relates to efficacy in one's ability to communicate with one's partner prior to and at sex initiation (Harden, 2014). To date, few studies have compared the frequency of PTCS on sensitive sex topics with the frequency of PTCS on reproductive and sexual health topics among early adolescents (DiIorio, McCarty, \& Pluhar, 2011). This may be particularly relevant for parents of African American descent, as the vast majority identify as Christian and thus, may hold religious beliefs that are in direct contrast to messages emphasizing 
the normality of sexual thoughts and behaviors during adolescence outside the context of marriage (O'Sullivan, Jaramillo, Moreau, \& Meyer-Bahlburg, 1999; Williams et al., 2015).

Parent-teen communication about sensitive sex topics may be critical to youths' sexual development, as few school or community-based sexual education programs aimed at youth cover such topics (Lightfoot, Taboada, Taggart, Tran, \& Burtaine, 2015; Widman et al., 2016). Failure to discuss sensitive sex topics could lead youth to believe that certain topics are offlimits and should not be discussed thereby affecting future sexual relationships. Research conflating parent-teen communication about reproductive and sexual health information with communication about sensitive sex topics could mask differences in prevalence of such conversations, leading to interventions that fail to address critical topics in promoting safer sex practices among vulnerable youth. This may be particularly problematic for young, rural African American youth who have an increased risk of experiencing adverse sexual health outcomes (Centers for Disease Control and Prevention, 2011, 2015; Epstein et al., 2014; Farmer et al., 2004). Therefore, the primary goals of the current study were to (a) identify topics discussed during PTCS; (b) determine whether there were differences in the frequency of conversations about reproductive and sexual health and sensitive sex topics based on both caregiver and youth reports; (c) determine which factors are associated with communication about each type of PTCS (i.e., reproductive and sexual health and sensitive sex topics); and (d) determine whether these factors differ as a function of who reports on PTCS (caregiver vs. youth).

\section{Method}

\section{Sample and Procedure}

This study was approved by the institutional review board at a large public university in the Southeastern part of the United States. It focuses on baseline data from a community-based HIV prevention program developed for African American youth aged 10 to 14 years and their caregivers called Teach One, Reach One. While the target age was between 10 and 14 years, 9 -year-olds who had birthdays prior to August 30 and 15-year-olds whose birthdays were after June 1 were also allowed to participate in the study. Project GRACE, an established community-based participatory research partnership created to address ethnic minority health disparities in rural communities, developed the intervention to delay sex initiation, increase safer sex practices, and to promote healthy dating relationships among early adolescents. The details regarding partnership and intervention development 
have been described elsewhere (Corbie-Smith et al., 2010, 2011; Ritchwood et al., 2015). In sum, we used intervention mapping to collectively develop an intervention guided by a composite conceptual framework that acknowledged multilevel factors in influencing HIV/STI risk among African American youth in rural communities. This integrated behavioral framework was composed of constructs from the theory of planned behavior (Ajzen, 1985), which addressed individual-level factors, and SCT (Bandura, 1989), which addressed factors related to the social environment.

We recruited participants from five rural counties in Eastern North Carolina between December 2008 and May 2012. Residents of these counties shared comparable population characteristics, including poverty rates and ethnic compositions (State Center for Health Statistics, Office of Healthy Carolinians/ Health Education, 2012). Youth were eligible if they self-identified as African American, were residents in the target counties, and were between the ages of 10 and 14 years. A small proportion of youth who identified as mixed race were also included in the current study, as community partners decided that youth and their caregivers should not be turned away if all other criteria were met. Caregivers were eligible if they were 18 years of age or older and responded affirmatively to the following question: "Are you a parent or caregiver to the participating African American youth?" This was critical, as caregivers and youth were required to enroll in the study as dyads. We recruited participants from local churches, schools, and other community organizations by distributing fliers and brochures, and through announcements on the radio and in newspapers.

Recruitment fliers stated that participants were sought for a "research study about dating, relationships, and communication." Along with the study description, eligibility criteria were included on fliers, which included whether they met residential and age requirements, there was interest from both the caregiver and youth, and they were able to commit necessary time to complete the study. Caregiver-youth dyads also completed an initial, 10-item screener for eligibility to verify that participants met study criteria. During the screening, potential participants were informed that they were being recruited for an HIV-prevention study and provided with additional detail regarding the study. Questions focused on residence in a target community, youth's age, and survey scheduling. Adult participants were asked, "Are you a parent or caregiver to an African American youth?" For the purposes of this study, we use the term caregiver when referring to adult study participants to acknowledge the diversity of relations between adults with caregiving responsibilities and youth in African American communities, with caregivers including biological parents, other relatives, legal guardians, or other adults with direct caregiving responsibilities for the youth. If interested and determined eligible, we asked caregivers to sign 
a consent form for themselves and their youth, while youth signed an assent form. In cases where the caregiver was not the legal guardian, parental permission was obtained. Prior to survey administration, the study team conducted cognitive interviews to ensure comprehension and adapted the language, where necessary, to ensure readability within our study population.

Both caregivers and youth completed a 1-hour self-administered baseline survey at a local community site (e.g., meeting room, library, etc.) that inquired about one's own attitudes and behaviors, as well as those of their participating youth (for caregivers) or caregiver (for youth). To address potential issues regarding confidentiality and low literacy, we used audio computer-assisted self-interview. Trained facilitators were available to assist participants when necessary. We piloted all measures for comprehension in our study populations and adapted the language, where necessary, to ensure readability within our population. Both caregivers and youth were initially offered $\$ 10$ each for completing the survey; however, this amount was increased to $\$ 30$ over the baseline time period to address recruitment challenges experienced in certain counties. Additional details regarding recruitment and training for the intervention study have been reported elsewhere, as the current article focuses only on baseline data (Corbie-Smith et al., 2010; Corbie-Smith et al., 2011; Dave et al., 2016; Ritchwood et al., 2017).

\section{Measures}

Sociodemographics. We assessed caregiver age, race, gender, and relationship to participating adolescent (e.g., biological parent, legal guardian), education level, and yearly income. We also assessed youth age and gender.

\section{Outcome Measure}

Parent-Teen Communication About Sex. An adapted version of the ParentAdolescent Communication Scale (Sales et al., 2008) assessed the extent to which both caregivers and youth reported PTCS and sexuality. The research team conducted confirmatory factor analyses on the original scale, which indicated that there were two independent factors: Parent-teen communication about reproductive and sexual health (caregiver $\alpha=.91$; youth $\alpha=.90$ ) and Parent-teen communication about sensitive sex topics (caregiver and youth $\alpha=.91)$, with high convergent validity $(r=.84, p<.001)$. The reproductive and sexual health subscale consisted of 10 items that inquired about the frequency with which caregivers had discussed various topics with their youth, including discussions about HIV/AIDS, menstruation, physical development, pregnancy, abortion, condom use, STIs, contraception, sex before 
marriage, and sexuality. The sensitive sex topics subscale consisted of seven items that inquired about the frequency with which caregivers had discussed more topics related to the pleasurable aspects of sex and sexuality including sexual desire and satisfaction, type of sex (i.e., vaginal, oral, or anal sex), masturbation, and nocturnal emission. Responses for both subscales range from 0 (never) to 3 (very often), with higher scores indicating more frequent communication.

\section{Independent Variables}

Permissive Attitude Toward Sex Initiation. This scale, which was adapted from a measure developed by Basen-Engquist et al. (1998), assessed attitudes toward delay in sex initiation. The four-item scale $(\alpha=.74)$ included statements such as, "I believe 10- to 11-year-olds should wait until they are older before they have sex." Responses ranged from 0 (definitely yes) to 3 (definitely no), with higher scores indicating more permissive attitudes toward sex initiation.

Attitude Toward Parent-Teen Communication About Sex and Dating. Attitude toward parent-teen communication assessed caregivers' beliefs regarding talking to early adolescents about dating and sex. The six-item scale $(\alpha=.89)$, developed de novo, included items such as, "It is important to talk to my child about abstinence." Responses range from 0 (strongly disagree) to 3 (strongly agree), with higher scores indicating positive attitudes regarding talking with the participating early adolescent about sex and dating.

Outcome Expectations Regarding Parent-Teen Communication About Sex. We used items from the Outcome Expectations of Parent-Teen Communication Scale (Barnes \& Olson, 1985) to assess caregivers' perceptions of what might happen as a result of talking with the participating early adolescent about dating and sex. This 10 -item scale $(\alpha=.84)$ included items such as, "If I talk with him or her about sex topics, I will be embarrassed," and, "If I talk with him or her about sex topics, he or she will be less likely to have sexual intercourse as a young teen." Responses range from 0 (strongly disagree) to 3 (strongly agree), with higher scores indicating more positive expectations regarding outcomes of PTCS.

Self-Efficacy for Parent-Teen Communication About Sex. The Self-Efficacy for Parental-Teen Communication Scale (DiIorio et al., 2001) assessed caregivers' belief in their own ability to talk with the participating youth about topics of a sexual nature such as, "How to put a condom on." The 16-item scale ( $\alpha$ 
$=.92$ ) included items such as, "You can always explain to the child in the program with you how to use birth control pills." Responses range from 0 (not sure at all) to 3 (completely sure). Higher scores indicate greater self-efficacy.

Open Parent-Teen Communication. The Open Family Communication subscale of the Parent-Adolescent Communication Scale (Barnes \& Olson, $1985)$ assessed caregivers' overall evaluation of communication with the participating youth. This 10 -item subscale $(\alpha=.85)$ measures the degree of openness and positive experiences in communicating with one's child. Responses range from 0 (strongly disagree) to 3 (strongly agree), with higher scores indicating more open communication.

For each scale, individual items were summed to create composite scores.

\section{Data Analysis}

Data were analyzed using SPSS, version 23. We used descriptive statistics (i.e., frequencies, means, standard deviations) to describe participant characteristics and used correlation coefficients to identify those variables that were significantly related to either of the outcome variables for inclusion in the final models. We conducted a paired samples $t$ test to examine differences in the frequency with which caregivers reported discussions about reproductive and sexual health topics when contrasted to their reports of discussions about sensitive sex topics with their youth. Next, we conducted two independent means $t$ tests to determine whether caregivers and youth differed in their perceptions of the frequency with which there was parent-teen communication about reproductive and sexual health topics and sensitive sex topics, separately. Last, four linear regression models were conducted to examine the effects of youth age and gender, caregiver permissive attitude toward sex initiation, attitude toward PTCS and dating, open parent-teen communication, and self-efficacy for PTCS on caregiver reports of parent-teen communication about reproductive and sexual health topics (Model 1) and sensitive sex topics (Model 2), as well as the frequency of youth reports of parent-teen communication about reproductive and sexual health topics (Model 3) and sensitive sex topics (Model 4). Caregiver sex, relation to youth, income, and education were included as covariates in all models. If individual covariates were not significantly related to the outcome variable once included in the model, they were later removed to generate a more parsimonious model. Statistical significance for the regression analyses was defined as $p<.05$. 


\section{Results}

Table 1 provides a summary of baseline demographic characteristics of the 465 caregiver-youth dyads. Caregivers and youth primarily identified as African American and were on average 36.18 years (biological: $M=37.0$, $S D=7.5$; other relative: $M=37.6, S D=16.6$; nonrelative: $M=32.8, S D=$ $13.5)$ and 12.55 years of age, respectively, and female. Most caregivers were the biological parent of the participating youth, reported some college/technical school education and had an average annual income of less than $\$ 20,000$. Overall, caregivers reported positive attitudes toward PTCS $(M=15.49, S D$ $=3.18$ ), high self-efficacy regarding communicating with their youth about sex $(M=39.0, S D=8.80)$, and less permissive attitudes toward sex initiation $(M=0.44, S D=1.40$; Table 2). Caregivers also reported moderate levels of positive outcome expectations regarding PTCS $(M=21.70, S D=4.33)$ and open parent-teen communication $(M=21.61, S D=4.57)$. However, they reported relatively low levels of actual parent-teen communication about reproductive and sexual health $(M=17.50, S D=8.53)$ and sensitive sex top$\operatorname{ics}(M=6.13, S D=6.37)$.

Sexual health topics were grouped into the two communication subscales: reproductive and sexual health topics and sensitive sex topics. Table 3 summarizes frequency of reports of parent-teen communication about each sexual health topic. Most caregivers reportedly discussed the following reproductive and sexual health topics with their youth at least a few times: physical development, HIV/AIDS, premarital sex, STIs, condom use, homosexuality, pregnancy, contraception, and menstruation. On the other hand, caregivers reported discussing the following sensitive sex topics with their youth at least a few times: sexual desire, vaginal sex, sexual satisfaction, oral sex, masturbation, anal sex, and nocturnal emission.

A large percentage of youth reported discussions of the following reproductive and sexual health topics with their caregivers at least a few times: physical development, menstruation, HIV/AIDS, pregnancy, STIs, premarital sex, condom use, contraception, and homosexuality. Few youth reported that they discussed the following sensitive sex topics with their caregiver at least a few times: sexual desire, sexual satisfaction, oral sex, vaginal sex, masturbation, anal sex, and nocturnal emission.

Caregivers reported more frequent discussions about reproductive and sexual health topics $(M=1.75, S D=0.85)$ than sensitive sex topics $(M=$ $0.85, S D=0.90) ; t(428)=23.13, p<.001$. Caregivers and youth differed in their assessments of how frequently reproductive and sexual health topics and sensitive sex topics were discussed. Caregivers, for instance, reported more frequent discussions about both reproductive and sexual health, 
Table I. Demographic Characteristics of Youth and Caregivers.

\begin{tabular}{|c|c|c|}
\hline & Youth & Caregivers \\
\hline Age (years), $M(S D$, range) & $12.55(1.42,9.6-15.4)$ & $36.18(11.84,18-80)$ \\
\hline \multicolumn{3}{|l|}{ Gender, \% (n) } \\
\hline Male & $44.5(207)$ & 19.1 (83) \\
\hline Female & $55.5(258)$ & $80.9(352)$ \\
\hline \multicolumn{3}{|l|}{ Race, \% (n) } \\
\hline African American & $89.8(422)$ & $90.7(45 I)$ \\
\hline Unspecified & $6.3(30)$ & $0.6(3)$ \\
\hline \multicolumn{3}{|l|}{ Ethnicity, \% (n) } \\
\hline Hispanic/Latino & $8.1(33)$ & $2.7(13)$ \\
\hline Non-Hispanic/Latino & $91.9(374)$ & $97.3(472)$ \\
\hline \multicolumn{3}{|l|}{ Relation to the youth, $\%(n)$} \\
\hline Parent & - & $54.7(285)$ \\
\hline Relative & - & $19.5(96)$ \\
\hline Nonrelative & - & $25.7(127)$ \\
\hline \multicolumn{3}{|l|}{ Education, \% (n) } \\
\hline 5th Grade or less & $22.2(103)$ & - \\
\hline 6th-8th Grade & $57(265)$ & - \\
\hline 9th-12th Grade & $20.8(97)$ & - \\
\hline Some high school or less & - & $21.7(108)$ \\
\hline High school & - & $33.9(168)$ \\
\hline Some college/technical school & - & $26.2(130)$ \\
\hline College/higher & - & I8.1 (90) \\
\hline \multicolumn{3}{|l|}{ Yearly income, \% (n) } \\
\hline$<\$ 5,000$ & - & $22.5(\mathrm{I} I 2)$ \\
\hline$\$ 5,000-\$ 19,999$ & - & $30.8(153)$ \\
\hline$\$ 20,000-\$ 39,999$ & - & $21.9(109)$ \\
\hline$\$ 40,000-\$ 59,999$ & - & $9.7(48)$ \\
\hline$\$ 60,000-\$ 79,999$ & - & $3.8(19)$ \\
\hline$\$ 80,000$ or more & - & $2.4(12)$ \\
\hline
\end{tabular}

Note. Totals do not sum to the sample size because of missing data and rounding.

caregiver $M=1.75, S D=.85$; youth $M=1.22, S D=0.87 ; t(458)=9.26$, $p<.001$; Cohen's $d=.62$, and sensitive sex topics, caregiver $M=0.90, S D=$ 0.92 ; youth $M=0.55, S D=0.78 ; t(438)=6.05, p<.001$; Cohen's $d=.41$, than their youth.

In our adjusted analyses focused on caregiver reports, we found that the overall model was significant, $F(8,427)=15.19 ; p \leq .001 ; R^{2}=.23$, such that higher levels of parent-teen communication about reproductive and sexual 
Table 2. Descriptive Statistics for Baseline PTCS-Related Measures.

\begin{tabular}{|c|c|c|c|c|}
\hline Construct & Measure name & $M(S D)$ & $\begin{array}{l}\text { Number } \\
\text { of items }\end{array}$ & $\begin{array}{l}\text { Actual } \\
\text { response } \\
\text { range }\end{array}$ \\
\hline \multirow[t]{2}{*}{$\begin{array}{l}\text { Caregiver } \\
\text { outcomes }\end{array}$} & $\begin{array}{l}\text { PTC about sensitive } \\
\text { sexual topics }\end{array}$ & $6.13(6.37)$ & 7 & $0-21$ \\
\hline & $\begin{array}{l}\text { PTC about } \\
\text { reproductive and } \\
\text { sexual health }\end{array}$ & $17.50(8.53)$ & 10 & $0-30$ \\
\hline \multirow[t]{2}{*}{ Youth outcomes } & $\begin{array}{l}\text { PTC about sensitive } \\
\text { sexual topics }\end{array}$ & $3.4 I(4.74)$ & 7 & $0-18$ \\
\hline & $\begin{array}{l}\text { PTC reproductive and } \\
\text { sexual health }\end{array}$ & $12.84(8.80)$ & 10 & $0-30$ \\
\hline \multirow[t]{2}{*}{ Attitudes } & PTCS & $15.49(3.18)$ & 6 & $0-18$ \\
\hline & $\begin{array}{l}\text { Permissive attitudes } \\
\text { toward sex initiation }\end{array}$ & $0.44(1.40)$ & 4 & $0-9$ \\
\hline $\begin{array}{l}\text { Outcome } \\
\text { expectations }\end{array}$ & PTCS & $21.70(4.33)$ & 10 & $0-30$ \\
\hline Self-efficacy & PTCS & $39.00(8.80)$ & 16 & $0-48$ \\
\hline $\begin{array}{l}\text { Relationship } \\
\text { quality }\end{array}$ & Open PTC & 21.61 (4.57) & 10 & $0-30$ \\
\hline
\end{tabular}

Note. PTCS $=$ parent-teen communication about sex.

health topics was associated with older youth age more positive attitudes toward PTCS, greater self-efficacy for PTCS, and open communication style (Table 4). Regarding communication about sensitive sex topics, the overall model was significant, $F(11,419)=7.40 ; p \leq .001 ; R^{2}=.14$. In this model, only open communication style and greater self-efficacy for PTCS were associated with greater communication about sensitive sex topics (Table 4). In our unadjusted model focused on youth reports, we found that the overall model was significant, $F(7,359)=7.58 ; p<.001 ; R^{2}=.13$, such that higher levels of parent-teen communication about reproductive and sexual health topics was associated with older youth age and being female (see Table 5). Regarding communication about sensitive sex topics, the overall model was significant, $F(7,348)=2.85 ; p=.007 ; R^{2}=.06$. In this model, only older age was associated with greater communication about sensitive sex topics (Table 5).

\section{Discussion}

Caregivers of rural, African American early adolescents reported more frequent discussions about reproductive and sexual health topics than sensitive 


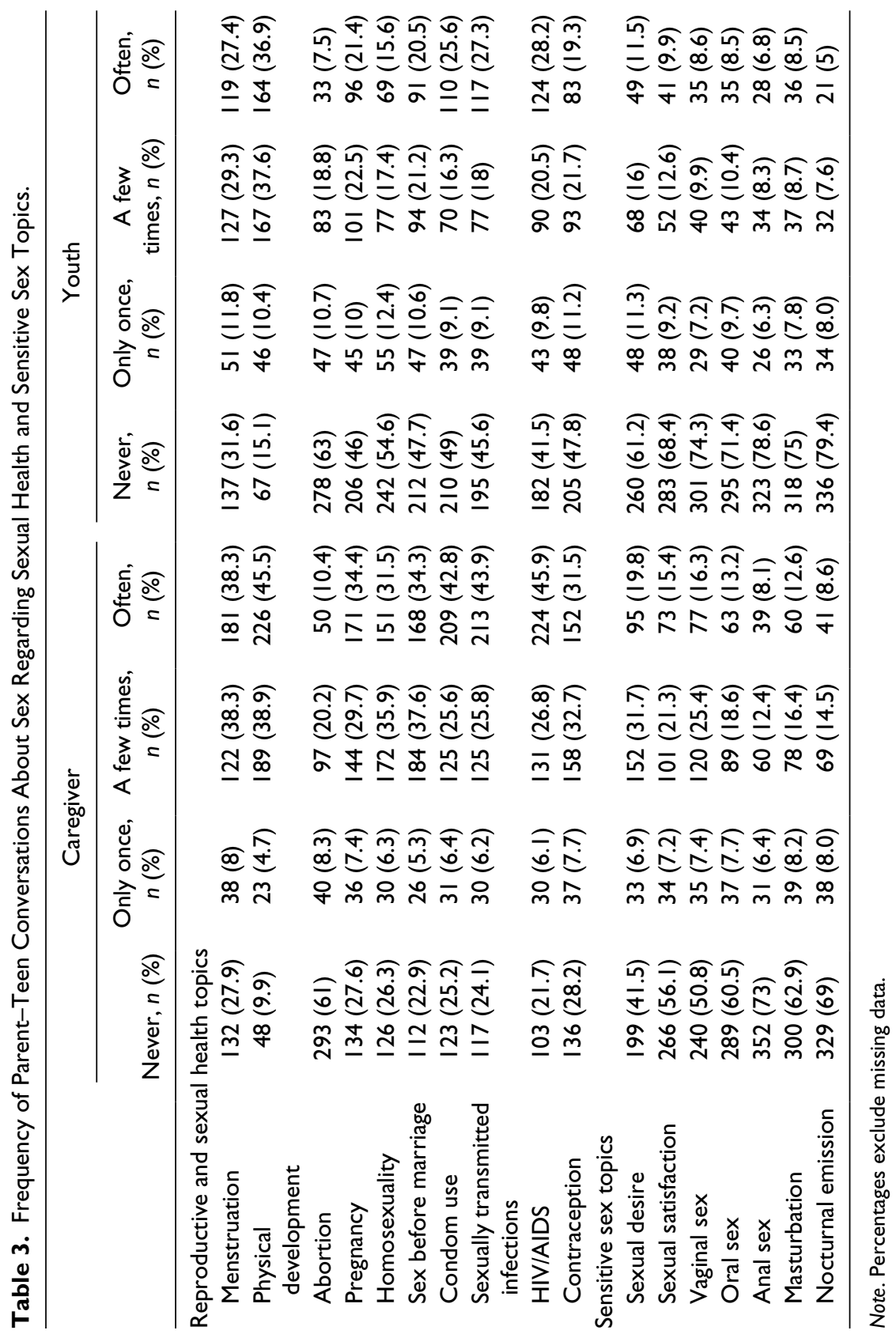


Table 4. Factors Associated With Caregivers' Reports of Parent-Teen Communication About Reproductive and Sexual Health and Sensitive Sex Topics.

\begin{tabular}{|c|c|c|c|c|}
\hline \multirow[b]{3}{*}{ Variable } & \multicolumn{4}{|c|}{ Caregiver report } \\
\hline & \multicolumn{2}{|c|}{$\begin{array}{l}\text { Reproductive and sexual } \\
\text { health topics }\end{array}$} & \multicolumn{2}{|c|}{ Sensitive sex topics } \\
\hline & $\beta(S E)$ & $p$ & $\beta(S E)$ & $p$ \\
\hline Youth age & $0.27(0.25)$ & .27 & $0.05(0.20)$ & .80 \\
\hline Youth gender & $-0.14(0.72)$ & .85 & $0.34(0.59)$ & .58 \\
\hline $\begin{array}{l}\text { Caregiver permissive } \\
\text { attitudes toward sex } \\
\text { initiation }\end{array}$ & $0.52(0.27)$ & .06 & $0.73(0.22)$ & $<.01 * *$ \\
\hline $\begin{array}{l}\text { Caregiver attitude } \\
\text { toward parent-teen } \\
\text { communication } \\
\text { about sex }\end{array}$ & $0.35(0.13)$ & $<.01 * *$ & $0.01(0.11)$ & .90 \\
\hline $\begin{array}{l}\text { Caregiver outcome } \\
\text { expectations }\end{array}$ & $0.12(0.10)$ & .23 & $0.11(0.09)$ & .21 \\
\hline $\begin{array}{l}\text { Caregiver self-efficacy } \\
\text { for parent-teen } \\
\text { communication } \\
\text { about sex }\end{array}$ & $0.27(0.05)$ & $<.001 * * *$ & $0.16(0.04)$ & $<.01 * *$ \\
\hline $\begin{array}{l}\text { Caregiver open } \\
\text { parent-teen } \\
\text { communication }\end{array}$ & $0.26(0.10)$ & $<.01 * *$ & $0.16(0.08)$ & $.04 *$ \\
\hline
\end{tabular}

Note. SE = standard error; Covariates: $\mathrm{RSH}$ model = parent gender; Sensitive sex model = relation to youth and parent gender.

$*_{p}<.05 . *_{p} \leq .01$. **** $=p \leq .00 \mathrm{I}$.

sex topics and overall, reported more frequent PTCS than their youth reported. We also found that the predictors of caregiver communication about reproductive and sexual health topics differed from the predictors of communication about sensitive sex topics. Older youth age, positive attitudes toward PTCS, self-efficacy for PTCS, and open communication style were associated with more frequent communication about reproductive and sexual health topics. Only self-efficacy for PTCS and open communication style were predictors of frequent parent-teen communication about sensitive sex topics. For youth, however, only older age and being females was associated with more frequent discussions about reproductive and sexual health topics and for discussions about sensitive sex topics, only older age was a significant predictor. Taken together, our findings are partially consistent with the integrated behavioral framework employed in this study. 
Table 5. Factors Associated With Youths' Reports of Parent-Teen

Communication About Reproductive and Sexual Health and Sensitive Sex Topics.

\begin{tabular}{|c|c|c|c|c|}
\hline \multirow[b]{3}{*}{ Variable } & \multicolumn{4}{|c|}{ Youth report } \\
\hline & \multicolumn{2}{|c|}{$\begin{array}{l}\text { Reproductive and } \\
\text { sexual health topics }\end{array}$} & \multicolumn{2}{|c|}{ Sensitive sex topics } \\
\hline & $\beta(S E)$ & $p$ & $\beta(S E)$ & $p$ \\
\hline Youth age & $2.13(0.31)$ & $<.001 * * *$ & $0.68(0.18)$ & $<.001 * * *$ \\
\hline Youth gender & $2.24(0.90)$ & $.01 * *$ & $-0.69(0.52)$ & .18 \\
\hline $\begin{array}{l}\text { Caregiver permissive attitudes } \\
\text { toward sex initiation }\end{array}$ & $0.82(0.33)$ & .80 & $-0.16(0.19)$ & .40 \\
\hline $\begin{array}{l}\text { Caregiver attitude toward } \\
\text { parent-teen communication } \\
\text { about sex }\end{array}$ & $0.07(0.15)$ & .65 & $-0.12(0.09)$ & .18 \\
\hline $\begin{array}{l}\text { Caregiver outcome } \\
\text { expectations }\end{array}$ & $-0.01(0.13)$ & .96 & $0.01(0.07)$ & .88 \\
\hline $\begin{array}{l}\text { Caregiver self-efficacy for } \\
\text { parent-teen communication } \\
\text { about sex }\end{array}$ & $0.05(0.06)$ & .40 & $0.06(0.03)$ & .09 \\
\hline $\begin{array}{l}\text { Caregiver open parent-teen } \\
\text { Communication }\end{array}$ & $-0.09(0.12)$ & .48 & $0.003(0.07)$ & .96 \\
\hline
\end{tabular}

Note. $S E$ = standard error. Caregiver covariates were not included in these models due to no significant relationship between individual variables and the outcome variable.

$* p<.05$. ** $\leq .01$. *** $p \leq .001$.

Our findings regarding discordance in caregiver-youth reports of communication on health topics are consistent with prior research (Grills \& Ollendick, 2002; Hadley et al., 2009; Miller, Kotchick, Dorsey, Forehand, \& Ham, 1998; Xiao, Li, \& Stanton, 2011). One study examining the concordance in reports of mother-teen sexual communication reported low correlations, ranging from .07 to .28 (Jaccard., 1998). Other studies found low rates of concordance between ethnic minority caregivers and youth regarding the frequency with which various sexual health topics were discussed (O'Sullivan et al., 1999; Ritchwood, Penn, Peasant, Albritton, \& Corbie-Smith, 2017). Discordant responses may be due to the way in which information is communicated with youth, such that caregivers with lower self-efficacy, poorer communication skills, and greater discomfort with PTCS may use language that is less clear and descriptive, expecting youth to pick up on conversational cues (Ritchwood, Penn, et al., 2017; Wilson, Dalberth, Koo, \& Gard, 2010). From an adolescent perspective, vague and nonexplicit communications may not be perceived as sexual communication, and could lead youth to be less attentive during such 
discussions (Ritchwood, Powell, et al., 2017). These discrepancies are important, considering that previous work with early adolescents has shown that significant discordancy between mother child sexual attitudes, along with youths' tendency to misperceive their mothers' attitudes about sex, could be connected to greater sexual risk among early adolescents and is likely the result of ineffective or lack of PTCS (Gound et al., 2007).

The fact that the majority of caregivers reported more frequent communication with their youth about reproductive and sexual health topics and significantly fewer reported communicating with their youth about sensitive sex topics is important. There are several potential explanations for these findings. First, discussing sensitive sex topics may require caregivers to acknowledge that their youth are sexual beings and thus, normalize their youths' sexual nature, which may be inconsistent with caregivers' beliefs and attitudes (Ritchwood, Powell, et al., 2017). Second, it is possible that caregivers in our study did not believe that such information was relevant or appropriate for early adolescents, as a significant proportion of caregivers in this study also reported low to moderate levels of PTCS about reproductive and sexual health topics. As such, we could expect that these caregivers would also report little or no communication about sensitive sex topics. Low communication regarding both topics could be related to caregiver discomfort, as well as their attitudes and religious beliefs, which may be inconsistent with providing certain information about sex with youth of a certain age (e.g., Ritchwood, Powell, et al., 2017). Caregivers might also underestimate their youths' interest or participation in sexual activities (O'Donnell et al., 2008; Pariera, 2016). Specifically, caregivers were more likely to emphasize topics that were more strongly associated with prevention of adverse sexual outcomes (e.g., abortion, pregnancy, STIs) or that required more practical and specific instructions (e.g., menstruation, physical development). However, failure to discuss sensitive topics could be an important omission on the part of caregivers of rural African American youth, as they tend to report earlier ages of sex initiation than other youth though the reasons for this are complex (Biello et al., 2012). Providing youth with age and culturally appropriate information about sensitive sex topics and continuing such discussions over the course of adolescence could facilitate a comprehensive understanding of sex and sexuality and delay sex initiation. Such efforts could lead early adolescents to: develop greater knowledge about their sexual development; have greater self-efficacy related to navigating their sexual desires and satisfaction; and be less likely to engage in risky sexual behavior (DiIorio, Pluhar, \& Belcher, 2003; Ritchwood, Powell, et al., 2017).

Our findings regarding predictors of parent-teen communication about reproductive and sexual health topics were expected and supportive of 
previous research on this topic. The significance of youth age to PTCS, for example, was consistent with previous research (Eisenberg et al., 2006; Swain, Ackerman, \& Ackerman, 2006). It is possible that caregivers make judgments regarding the appropriateness of certain types of sexual information with their youth considering their youth's age, as well as perceived readiness for such discussions (Beckett et al., 2010). This assertion is consistent with previous findings that parents tended to delay PTCS until they became aware that their youth had a romantic partner (Eisenberg et al., 2006; Wilson et al., 2010).

In addition, our study illustrates the importance of self-efficacy for PTCS to both parent-teen communication about reproductive and sexual health topics and sensitive sex topics, such that caregivers who reported more confidence in their ability to talk to their children about sex were more likely to communicate about both topics. Collectively, our findings highlight the need to broaden caregivers' definition of PTCS to include sensitive sex topics; to promote the initiation of ongoing discussions about sex early and often; to facilitate self-efficacy for PTCS for both reproductive and sensitive sex topics; and to improve relationship quality between caregivers and rural African American early adolescents by means of providing caregivers with the skills to engage in an open communication style with their youth.

\section{Implications}

Despite the cross-sectional nature of this study, our findings have important implications for future research and intervention studies. First, the results of this study suggest that the frequency of parental communication about both reproductive and sexual health topics and sensitive sex topics may be a function of communication skills and efficacy. Should longitudinal studies support the current findings, there would be several suggestions for future interventions. First, future studies should consider building in intervention components that enable trained study confederates to provide caregivers with feedback regarding the way in which the sexual health information was communicated and how caregivers might improve. Interventions could also provide youth with opportunities to provide their caregivers with feedback, such that they are able to share with their caregiver regarding how information was received and interpreted. This could potentially address issues regarding high discordance rates in reports of PTCS between caregivers and youth. Moreover, interventions aimed at fostering caregivers' efficacy to communicate about a variety of sex topics among rural, African American caregivers and their youth should include skill-building activities that provide practical methods 
for caregivers to overcome challenges of talking with youth about sensitive sex topics (Guilamo-Ramos et al., 2008).

\section{Limitations}

These findings should be considered in the context of the study limitations. The caregivers in this study were predominantly rural African Americans and data were cross-sectional, thus limiting generalizability of these findings. However, these findings are extremely relevant to this high-risk population and additional longitudinal research on this topic could inform the development of future interventions. Similarly, the majority of participating caregivers were female. Though reflective of a significant proportion of rural African American households, the predominance of maternal caregivers could further limit the generalizability of findings, as we are unable to determine whether predictors might differ significantly for male caregivers. Third, questions regarding whether caregivers discussed specific topics do not provide insight into what was communicated. Previous qualitative research, however, has suggested that African American caregivers tended to focus on avoiding the consequences of sexual behavior rather than teaching their youth about sexual concepts (Akers, Schwarz, Borrero, \& CorbieSmith, 2010). Fourth, it is possible that our findings are influenced by self-selection bias, as individuals willing to participate in a survey on adolescent sexual health may differ from their peers. This, however, is a common concern with survey-based research. Last, a large proportion of the caregivers in the sample were not related to the participating youth. Given the significance of extended kinship networks within African American communities and our desire to acknowledge unique and diverse caregiving relationships in this community, we believed that it was critical that we allow nonrelated caregivers and youth to participate in the study. We did, however, control for the potential effects of such diverse relationships in our analyses.

\section{Conclusion}

Limitations notwithstanding, these findings are consistent with previous research and emphasize the importance of attitudes and self-efficacy in predicting PTCS (Wilson et al., 2010). Moreover, our findings extend the literature on this topic by illustrating the importance of open communication style, which was used as a proxy for relationship quality, for PTCS among rural African American families. Our findings support the differential examination 
of parent-teen communication about reproductive and sexual health topics versus sensitive topics, as this study demonstrated significant differences in topics covered, as well as predictors of the frequency of such discussions.

PTCS is most effective when it occurs before sex initiation and is content specific (Dilorio et al., 2003). Sex initiation occurs at an earlier age among rural youth compared with the general adolescent population (Milhausen et al., 2003) and these youth are at significant risk for STIs due to dense sexual networks among other factors (Adimora, Schoenbach, \& Doherty, 2006). Therefore, PTCS should occur early and often with these youth. There are a number of interventions aimed at improving PTCS and recent reviews have suggested that those that include caregivers are more effective than those that included either caregivers or youth only (see Akers et al., 2011; Sutton et al., 2014, for review). The Teach One, Reach One intervention, for example, contains both group sessions for caregivers and youth separately, as well as collectively to reinforce training and learning (Dave et al., 2016). More research, however, is needed to determine whether safe sex interventions for rural African American youth that employ caregivers should place emphasis on fostering positive attitudes and building self-efficacy related to PTCS, especially as it relates to sensitive sex topics. It is possible that tailored safe sex interventions that emphasize attitudes and self-efficacy for parentteen communication about both reproductive and sexual health topics and sensitive sex topics could empower rural, African American caregivers to initiate and maintain an open dialogue about sex with their youth, leading to reduced sexual risk and STIs. In addition to interventions that target individual families, it is also critical that efforts are made at the community level to encourage more acceptance and participation. While previous research has identified the challenges involved in community-based sexual education, there are many opportunities, including greater flexibility in the types of sexual topics that may be discussed given the limitations by select school districts in many rural counties, as well as cross-organizational collaboration and context-specific innovation and adaptation (e.g., Ott, Rouse, Resseguie, Smith, \& Woodcox, 2011).

\section{Acknowledgments}

We would like to acknowledge the contributions of our university-community partnership project.

\section{Declaration of Conflicting Interests}

The author(s) declared no potential conflicts of interest with respect to the research, authorship, and/or publication of this article. 


\section{Funding}

The author(s) disclosed receipt of the following financial support for the research, authorship, and/or publication of this article: This work was funded by grants from the National Institute on Minority Health and Health Disparities (R24MD001671), the University of North Carolina Center for AIDS Research (UNC CFAR P30 AI50410), and from the National Institute of Mental Health (R25MH083635). Author Tiarney D. Ritchwood was supported by the following grants during the preparation of this article: R25DA035692, R25MH087217, R25MH083635). Author Courtney Peasant was supported by a grant from the National Institute of Mental Health (T32MH020031). Author Tamara Taggart was supported by a fellowship from the National Institute of Allergy And Infectious Diseases of the National Institutes of Health (T32AI007001). Author Giselle Corbie-Smith was supported by a midcareer award in patient-oriented research (K24HL105493).

\section{References}

Adimora, A. A., Schoenbach, V. J., \& Doherty, I. A. (2006). HIV and African Americans in the Southern United States: Sexual networks and social context. Sexually Transmitted Diseases, 33, S39-S45. doi:10.1097/01.olq.0000228298.07826.68

Ajzen, I. (1985). From intentions to actions: A theory of planned behavior. In J. Kuhl (Ed.), Action control: From cognition to behavior (pp. 11-39). Berlin, Germany: Springer.

Akers, A. Y., Holland, C. L., \& Bost, J. (2011). Interventions to improve parental communication about sex: A systematic review. Pediatrics, 127, 494-510. doi:10.1542/peds.2010-2194

Akers, A. Y., Schwarz, E. B., Borrero, S., \& Corbie-Smith, G. (2010). Family discussions about contraception and family planning: A qualitative exploration of black parent and adolescent perspectives. Perspectives on Sexual and Reproductive Health, 42, 160-167. doi:10.1363/4216010

Aspy, C. B., Vesely, S. K., Oman, R. F., Rodine, S., Marshall, L., \& McLeroy, K. (2007). Parental communication and youth sexual behavior. Journal of Adolescence, 30, 449-466. doi:10.1016/j.adolescence.2006.04.007

Bandura, A. (1989). Human agency in social cognitive theory. American Psychologist, $44,1175-1184$.

Barnes, H. L., \& Olson, D. H. (1985). Parent-adolescent communication and the Circumplex Model. Child Development, 56, 438-447. doi:10.2307/1129732

Basen-Engquist, K., Mâsse, L. C., Coyle, K., Kirby, D., Parcel, G., Banspach, S., \& Nodora, J. (1998). Sexual risk behavior beliefs and self-efficacy scales. In C. M. Davis, W. L. Yarber, R. Bauserman, G. Schreer, \& S. Davis (Eds.), Handbook of sexuality-related measures (pp. 541-544). Thousand Oaks, CA: Sage.

Beckett, M., Elliott, M., Martino, S., Kanouse, D., Corona, R., Klein, D., \& Schuster, M. A. (2010). Timing of parent and child communication about sexuality relative to children's sexual behaviors. Pediatrics, 125, 34-42. doi:10.1542/ peds.2009-0806 
Biello, K. B., Kershaw, T., Nelson, R., Hogben, M., Ickovics, J., \& Niccolai, L. (2012). Racial residential segregation and rates of gonorrhea in the United States, 2003-2007. American Journal of Public Health, 102, 1370-1377. doi:10.2105/ AJPH.2011.300516

Bradley, H., Leichliter, J. S., \& Gift, T. L. (2013). Does discussing sexually transmissible infections or HIV with a parent increase condom use among young women using other contraceptive methods? Sexual Health, 10, 82-90. doi:10.1071/SH12091

Brody, G. H., McBride Murry, V., McNair, L., Chen, Y. F., Gibbons, F. X., Gerrard, M., \& Ashby Wills, T. (2005). Linking changes in parenting to parent-child relationship quality and youth self-control: The Strong African American Families Program. Journal of Research on Adolescence, 15, 47-69. doi:10.1111/j.15327795.2005.00086.x

Centers for Disease Control and Prevention. (2011). HIV Surveillance Report: Diagnoses of HIV infection and AIDS in the United States and dependent areas, 2009. Retrieved from https:/www.cdc.gov/hiv/pdf/statistics_2009_hiv_surveillance_report_vol_21.pdf

Centers for Disease Control and Prevention. (2015). Sexual risk behaviors: HIV, STD, and teen pregnancy prevention. Retrieved from http://www.cdc.gov/healthyyouth/sexualbehaviors

Corbie-Smith, G., Adimora, A. A., Youmans, S., Muhammad, M., Blumenthal, C., Ellison, A., . . Wynn, M. (2011). Project GRACE: A staged approach to development of a community-Academic partnership to address HIV in rural African American communities. Health Promotion Practice, 12(2), 293-302.

Corbie-Smith, G., Akers, A. Y., Blumenthal, C., Council, B., Wynn, M., Muhammad, M., . . . Stith, D. (2010). Intervention mapping as a participatory approach to developing an HIV prevention intervention in rural African American communities. AIDS Education and Prevention: Official Publication of the International Society for AIDS Education, 22, 184-202.

Dave, G., Ritchwood, T., Young, T. L., Isler, M. R., Black, A., Akers, A. Y., . . Stith, D. (2017). Evaluating Teach One Reach One: An STI/HIV risk-reduction intervention to enhance adult-youth communication about sex and reduce the burden of HIV/STI. American Journal of Health Promotion, 31, 465-475.

DiIorio, C., Dudley, W. N., Kelly, M., Soet, J. E., Mbwara, J., \& Sharpe Potter, J. (2001). Social cognitive correlates of sexual experience and condom use among 13- through 15-year-old adolescents. Journal of Adolescent Health, 29, 208-216. doi:10.1016/S1054-139X(00)00200-7

DiIorio, C., Pluhar, E., \& Belcher, L. (2003). Parent-child communication about sexuality: A review of the literature from 1980-2002. Journal of HIV/AIDS Prevention \& Education for Adolescents \& Children, 5, 7-32. doi:10.1300/J129v05n03_02

Dilorio, C. K., McCarty, F., \& Pluhar, E. (2011). Set the pace! Results of an HIV prevention intervention for mothers of young children. Journal of HIV/AIDS \& Social Services, 10, 290-310. doi:10.1080/15381501.2011.596768

Dittus, P., Miller, K. S., Kotchick, B. A., \& Forehand, R. (2004). Why parents matter! The conceptual basis for a community-based HIV prevention program for 
the parents of African American youth. Journal of Child and Family Studies, 13, 5-20. doi:10.1023/B:JCFS.0000010487.46007.08

Donaldson, A. A., Lindberg, L. D., Ellen, J. M., \& Marcell, A. V. (2013). Receipt of sexual health information from parents, teachers, and healthcare providers by sexually experienced U.S. adolescents. Journal of Adolescent Health, 53, 235240. doi:10.1016/j.jadohealth.2013.03.017

Dyson, S., \& Smith, E. (2012). "There are lots of different kinds of normal": Families and sex education-Styles, approaches and concerns. Sex Education, 12, 219229. doi:10.1080/14681811.2011.609053

Eisenberg, M. E., Sieving, R. E., Bearinger, L. H., Swain, C., \& Resnick, M. D. (2006). Parents' communication with adolescents about sexual behavior: A missed opportunity for prevention? Journal of Youth and Adolescence, 35, 893902. doi:10.1007/s10964-006-9093-y

Epstein, M., Bailey, J. A., Manhart, L. E., Hill, K. G., Hawkins, J. D., Haggerty, K. P., \& Catalano, R. F. (2014). Understanding the link between early sexual initiation and later sexually transmitted infection: Test and replication in two longitudinal studies. Journal of Adolescent Health, 54, 435-441. doi:10.1016/j. jadohealth.2013.09.016

Farmer, T. W., Price, L. N., O’Neal, K. K., Leung, M.-C., Goforth, J. B., Cairns, B. D., \& Reese, L. E. (2004). Exploring risk in early adolescent African American youth. American Journal of Community Psychology, 33, 51-59. doi:10.1023/ B:AJCP.0000014318.16652.30

Fishbein, M. (2000). The role of theory in HIV prevention. AIDS Care, 12, 273-278. Gound, M., Forehand, R., Long, N., Miller, K. S., Armistead, L., \& McNair, L. (2007). Attitude mismatching: Discrepancies in the sexual attitudes of African American mothers and their pre-adolescent children. AIDS and Behavior, 11, 113-122. doi:10.1007/s10461-006-9114-6

Grills, A. E., \& Ollendick, T. H. (2002). Issues in parent-child agreement: The case of structured diagnostic interviews. Clinical Child and Family Psychology Review, 5, 57-83. doi:10.1023/A:1014573708569

Guilamo-Ramos, V., Bouris, A., Lee, J., McCarthy, K. L., Micheal, S. L., Pitt-Barnes, S., \& Dittus, P. (2012). Parental influences on adolescent sexual risk behaviors: A structured literature review. Pediatrics, 130, e1313-e1325. doi:10.1542/ peds.2011-2066

Guilamo-Ramos, V., Jaccard, J., Dittus, P., \& Collins, S. (2008). Parent-adolescent communication about sexual intercourse: An analysis of maternal reluctance to communicate. Health Psychology, 27, 760-769. doi:10.1037/a0013833

Hadley, W., Brown, L. K., Lescano, C. M., Kell, H., Spalding, K., Diclemente, R., \& Donenberg, G. (2009). Parent-adolescent sexual communication: Associations of condom use with condom discussions. AIDS and Behavior, 13, 997-1004. doi:10.1007/s10461-008-9468-z

Harden, K. P. (2014). A sensitive sex framework for research on adolescent sexuality. Perspectives on Psychological Science, 9, 455-469. doi:10.1177/ 1745691614535934 
Jaccard, J., Dittus, P. J., \& Gordon, V. V. (1998). Parent-adolescent congruency in reports of adolescent sexual behavior and in communications about sexual behavior. Child Development, 69(1), 247-261.

Jaccard, J., Dodge, T., \& Dittus, P. (2002). Parent-adolescent communication about sex and birth control: A conceptual framework. New Directions for Child and Adolescent Development, 2002(97), 9-42. doi:10.1002/cd.48

Jerman, P., \& Constantine, N. A. (2010). Demographic and psychological predictors of parent-adolescent communication about sex: A representative statewide analysis. Journal of Youth and Adolescence, 39, 1164-1174. doi:10.1007/s10964010-9546-1

Lammers, C., Ireland, M., Resnick, M., \& Blum, R. (2000). Influences on adolescents' decision to postpone onset of sexual intercourse: A survival analysis of virginity among youths aged 13 to 18 years. Journal of Adolescent Health, 26, 42-48. doi:10.1016/S1054-139X(99)00041-5

Lightfoot, A. F., Taboada, A., Taggart, T., Tran, T., \& Burtaine, A. (2015). "I learned to be okay with talking about sex and safety": Assessing the efficacy of a theatrebased HIV prevention approach for adolescents in North Carolina. Sex Education, 15, 348-363. doi:10.1080/14681811.2015.1025947

Milhausen, R. R., Crosby, R., Yarber, W. L., DiClemente, R. J., Wingood, G. M., \& Ding, K. (2003). Rural and nonrural African American high school students and STD/HIV sexual-risk behaviors. American Journal of Health Behavior, 27, 373379. doi:10.5993/AJHB.27.4.9

Miller, K. S., Fasula, A. M., Dittus, P., Wiegand, R. E., Wyckoff, S. C., \& McNair, L. (2009). Barriers and facilitators to maternal communication with preadolescents about age-relevant sexual topics. AIDS and Behavior, 13, 365-374. doi:10.1007/ s10461-007-9324-6

Miller, K. S., Fasula, A. M., Lin, C. Y., Levin, M. L., Wyckoff, S. C., \& Forehand, R. (2012). Ready, set, go: African American preadolescents' sexual thoughts, intentions, and behaviors. Journal of Early Adolescence, 32, 293-307. doi:10.1177/027243161039324

Miller, K. S., Kotchick, B. A., Dorsey, S., Forehand, R., \& Ham, A. Y. (1998). Family communication about sex: What are parents saying and are their adolescents listening? Family Planning Perspectives, 30, 218-235. doi:10.2307/2991607

Miller, K. S., Lin, C. Y., Poulsen, M. N., Fasula, A., Wyckoff, S. C., Forehand, R., Armistead, L. (2011). Enhancing HIV communication between parents and children: Efficacy of the Parents Matter! Program. AIDS Education and Prevention, 23, 550-563. doi:10.1521/aeap.2011.23.6.550

O’Donnell, L., Stueve, A., Duran, R., Myint-U, A., Agronick, G., San Doval, A., \& Wilson-Simmons, R. (2008). Parenting practices, parents' underestimation of daughters' risks, and alcohol and sexual behaviors of urban girls. Journal of Adolescent Health, 42, 496-502. doi:10.1016/j.jadohealth.2007.10.008

O’Donnell, L., Wilson-Simmons, R., Dash, K., Jeanbaptiste, V., Myint, U. A., Moss, J., \& Stueve, A. (2007). Saving sex for later: Developing a parent-child com- 
munication intervention to delay sexual initiation among young adolescents. Sex Education, 7, 107-125. doi:10.1080/14681810701264441

O’Sullivan, L. F., Jaramillo, B. M., Moreau, D., \& Meyer-Bahlburg, H. F. (1999). Mother-daughter communication about sexuality in a clinical sample of Hispanic adolescent girls. Hispanic Journal of Behavioral Sciences, 21, 447-469.

Ott, M. A., Rouse, M., Resseguie, J., Smith, H., \& Woodcox, S. (2011). Communitylevel successes and challenges to implementing adolescent sex education programs. Maternal and Child Health Journal, 15, 169-177. doi:10.1007/ s10995-010-0574-y

Pariera, K. L. (2016). Barriers and prompts to parent-child sexual communication. Journal of Family Communication, 16, 277-283. doi:10.1080/15267431.2016.1 181068

Regnerus, M. D., \& Luchies, L. B. (2006). The parent-child relationship and opportunities for adolescents' first sex. Journal of Family Issues, 27, 159-183. doi:10. 1177/0192513X05281858

Ritchwood, T. D., Albritton, T., Akers, A. Y., Dave, G., Carthron, D., Adimora, A., Corbie-Smith, G. (2015). The effect of the TORO intervention on acceptance of couple violence among rural, African American youth. Journal of Child and Family Studies, 24(12), 3805-3815. doi:10.1007/s10826-015-0188-5

Ritchwood, T. D., Dave, G., Carthron, D. C., Roman Isler, M., Blumenthal, C., Wynn, M., Corbie-Smith, G. (2016). Adolescents and caregivers as lay health advisors in a community-based risk reduction intervention for youth: Baseline data from Teach One Reach One. AIDS Care, 28(4), 537-542. doi:10.1080/09540121.201 5.1112348

Ritchwood, T. D., Penn, D. C., Peasant, C., Albritton, T., \& Corbie-Smith, G. (2017). Condom use self-efficacy among younger rural adolescents: The influence of parent-teen communication, and knowledge of and attitudes toward condoms. Journal of Early Adolescence, 37, 267-283. doi:10.1177/0272431615599065

Ritchwood, T. D., Powell, T. W., Metzger, I. W., Dave, G., Corbie-Smith, G., Atujuna, M., Akers, A. Y. (2017). Understanding the relationship between religiosity and caregiver-adolescent communication about sex within African-American Families. Journal of Child and Family Studies, 26, 2979-2989. doi:10.1007/ s10826-017-0810-9

Robert, A. C., \& Sonenstein, F. L. (2010). Adolescents' reports of communication with their parents about sexually transmitted diseases and birth control: 1988, 1995, and 2002. Journal of Adolescent Health, 46, 532-537. doi:10.1016/j.jadohealth.2009.11.201

Sales, J. M., Milhausen, R. R., Wingood, G. M., DiClemente, R. J., Salazar, L. F., \& Crosby, R. A. (2008). Validation of a Parent-Adolescent Communication Scale for use in STD/HIV prevention interventions. Health Education \& Behavior, 35, 332-345. doi:10.1177/1090198106293524

State Center for Health Statistics, Office of Healthy Carolinians/Health Education. (2012). North Carolina resident population estimates. Raleigh, NC: State Center for Health Statistics. 
Sutton, M. Y., Lasswell, S. M., Lanier, Y., \& Miller, K. S. (2014). Impact of parentchild communication interventions on sex behaviors and cognitive outcomes for Black/African-American and Hispanic/Latino youth: A systematic review, 1988-2012. Journal of Adolescent Health, 54, 369-384. doi:10.1016/j.jadohealth.2013.11.004

Swain, C. R., Ackerman, L. K., \& Ackerman, M. A. (2006). The influence of individual characteristics and contraceptive beliefs on parent-teen sexual communications: A structural model. Journal of Adolescent Health, 38, 753.e9-753.e18. doi:10.1016/j.jadohealth.2005.08.015

Szapocznik, J., \& Coatsworth, J. D. (1999). An ecodevelopmental framework for organizing the influences on drug abuse: A developmental model of risk and protection. In M. D. Glantz \& C. Hartel (Eds.), Drug abuse: Origins \& interventions (pp. 331-366). Washington, DC: American Psychological Association.

Widman, L., Choukas-Bradley, S., Helms, S. W., Golin, C. E., \& Prinstein, M. J. (2014). Sexual communication between early adolescents and their dating partners, parents, and best friends. Journal of Sex Research, 51, 731-741. doi:10.108 0/00224499.2013.843148

Widman, L., Choukas-Bradley, S., Noar, S. M., Nesi, J., \& Garrett, K. (2016). Parentadolescent sexual communication and adolescent safer sex behavior: A metaanalysis. JAMA Pediatrics, 170, 52-61. doi:10.1001/jamapediatrics.2015.2731

Williams, T. T., Pichon, L. C., \& Campbell, B. (2015). Sexual health communication with religious African American families. Health Communication, 30, 328-338. doi:10.1080/10410236.2013.856743

Wilson, E. K., Dalberth, B. T., Koo, H. P., \& Gard, J. C. (2010). Parents' perspectives on talking to preteenage children about sex. Perspectives on Sexual and Reproductive Health, 42, 56-63. doi:10.1363/4205610

Wyckoff, S. C., Miller, K. S., Forehand, R., Bau, J. J., Fasula, A., Long, N., \& Armistead, L. (2008). Patterns of sexuality communication between preadolescents and their mothers and fathers. Journal of Child and Family Studies, 17, 649-662. doi:10.1007/s10826-007-9179-5

Xiao, Z., Li, X., \& Stanton, B. (2011). Perceptions of parent-adolescent communication within families: It is a matter of perspective. Psychology, Health \& Medicine, 16, 53-65. doi:10.1080/13548506.2010.521563 